\title{
Treatment of bleeding from a portion of pancreatojejunostomy after pancreaticoduodenectomy with division of the splenic vein: two case reports
}

Hiroki Kushiya ${ }^{1}$, Takehiro Noji ${ }^{*}$ (D), Daisuke Abo², Takeshi Soyama², Kimitaka Tanaka', Yoshitsugu Nakanishi', Toshimichi Asano', Toru Nakamura', Takahiro Tsuchikawa', Keisuke Okamura ${ }^{1}$ and Satoshi Hirano

\begin{abstract}
Background: There is no definitive strategy for gastrointestinal bleeding due to left-sided portal hypertension after pancreaticoduodenectomy (PD) for pancreatic cancer (PC) with concomitant portal vein resection (PVR).

Case presentation: Case 1: A 70-year-old woman underwent a PD for PC with PVR. Seven years after her surgery, she suffered severe anemia with suspected gastrointestinal bleeding. Computed tomography scan (CT) revealed varices at a portion of the pancreaticojejunostomy (PJ). Angiography revealed that splenic venous flow drained into the varices and then into the portal vein. A diagnosis of bleeding varices of the PJ due to left-sided portal hypertension was made. Following a partial splenic artery embolization, her anemia improved.

Case 2: An 80-year-old male underwent a PD for pancreatic head cancer combined with resection of the confluence of the portal and splenic veins with a reconstruction between the portal and superior mesenteric veins. Eighteen months after his surgery, he developed melena with negative endoscopy findings in his large and small bowel. CT revealed varices at the site of the PJ that communicated with the jejunal and portal veins. He underwent obliteration of the varices via a trans-portal-venous approach. As a result, he remained without melena until he died of PC 17 months after the embolization.
\end{abstract}

Conclusions: Left-sided portal hypertension following a PD with bleeding varices can be treated by interventional radiology with minimal invasiveness.

Keywords: Pancreaticoduodenectomy, Left-sided portal hypertension, Interventional radiology, Intestinal bleeding

\section{Background}

Left-sided portal hypertension (LSPH) is a localized form of portal hypertension that occurs as a result of an isolated thrombosis or obstruction of the splenic vein (SV) [1]. $\mathrm{LSPH}$ is different from $\mathrm{PH}$ in terms of normal liver function and no obstruction of the portal vein (PV) [2]. Also, it has been reported that LSPH occurred after pancreaticoduodenectomies (PDs) without SV reconstructions [3, 4]. Herein, we discuss two different types of interventional radiology (IVR) methods for treating intestinal bleeding

\footnotetext{
* Correspondence: drnoji@med.hokudai.ac.jp

${ }^{1}$ Department of Gastroenterological Surgery 2, Hokkaido University Faculty of Medicine, Kita 15 Nishi 7, Kita-ku, Sapporo, Hokkaido 060-8638, Japan Full list of author information is available at the end of the article
}

from pancreaticojejunostomies (PJs) due to LSPH after PDs with concomitant PV resections (PVRs).

\section{Case presentation \\ Case 1}

A 70-year-old woman underwent PD for pancreatic cancer (PC) with a concomitant PVR. She also underwent an $\mathrm{SV}$ and inferior mesenteric vein (IMV) resection. The side-to-end anastomosis was performed only between the SV and IMV (Fig. 1). She discharged without complications. Seven years after her surgery, she suffered severe anemia and gastrointestinal bleeding was suspected. However, we could not find a bleeding lesion using gastrointestinal endoscopes. Computed tomography $(\mathrm{CT})$ revealed 


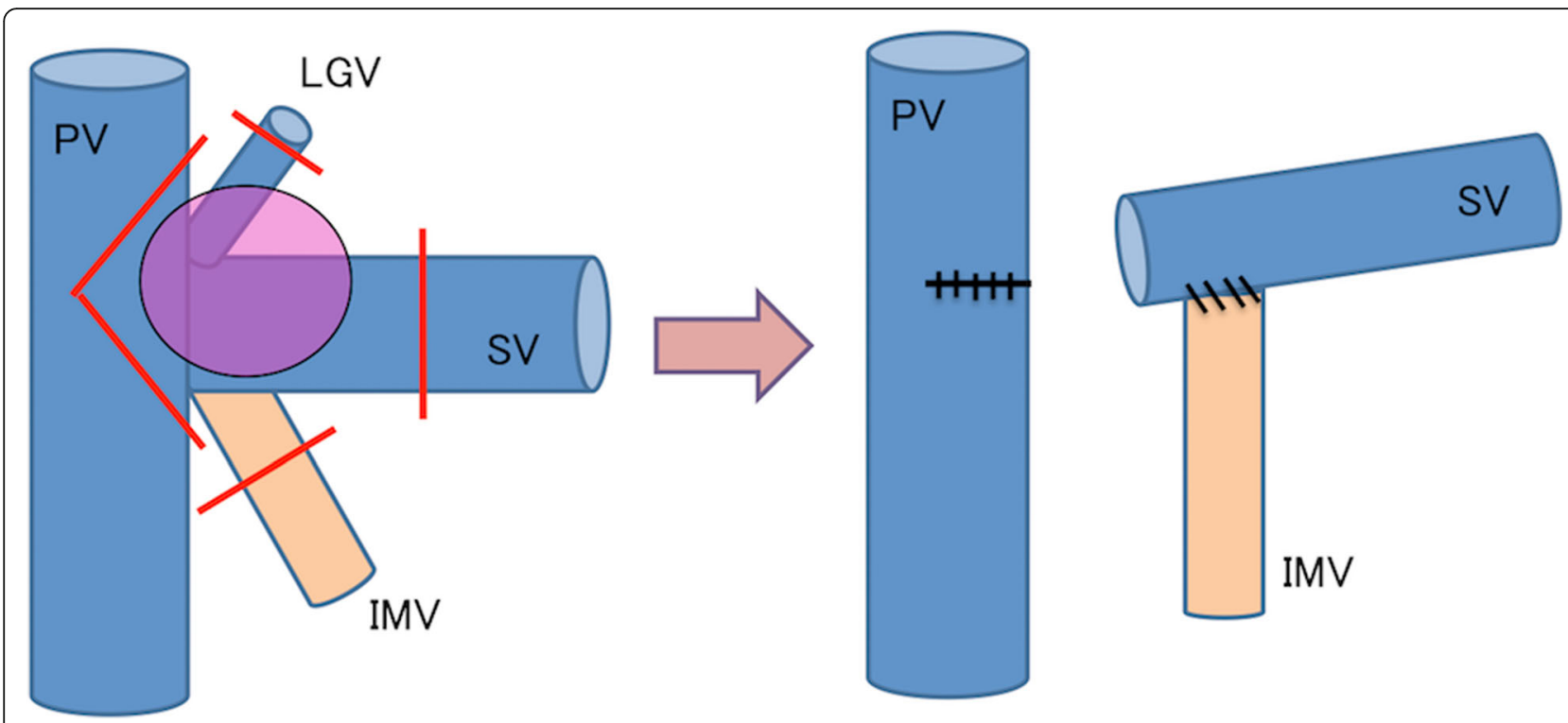

Fig. 1 Pancreaticoduodenectomy combined with a concomitant resection of the confluence of the PV and SV. Side-to-end anastomosis was performed between the SV and IMV. PV portal vein, LGV left gastric vein, SV splenic vein, IMV inferior mesenteric vein

varices at a portion of the PJ (Fig. 2a, b). Angiography revealed that splenic venous flow drained into the varices around the PJ and then ran into the PV (Fig. 2c). Therefore, we diagnosed that her anemia originated from varices at the PJ with LSPH.

We selected partial splenic artery embolization (PSE) for hemostasis. At the first stage, we embolized $70 \%$ of the splenic arterial flow. Ten months after the first stage PSE, she again complained of melena and anemia, for which we performed a second stage PSE (embolized 90\% of splenic artery flow). Although follow-up CT at 3 years after first stage PSE showed the varices around the PJ (Fig. 3), her bleeding episodes have not been observed during a 2-year follow-up period.

\section{Case 2}

An 80-year-old male underwent a PD for pancreatic head cancer combined with resection of the confluence
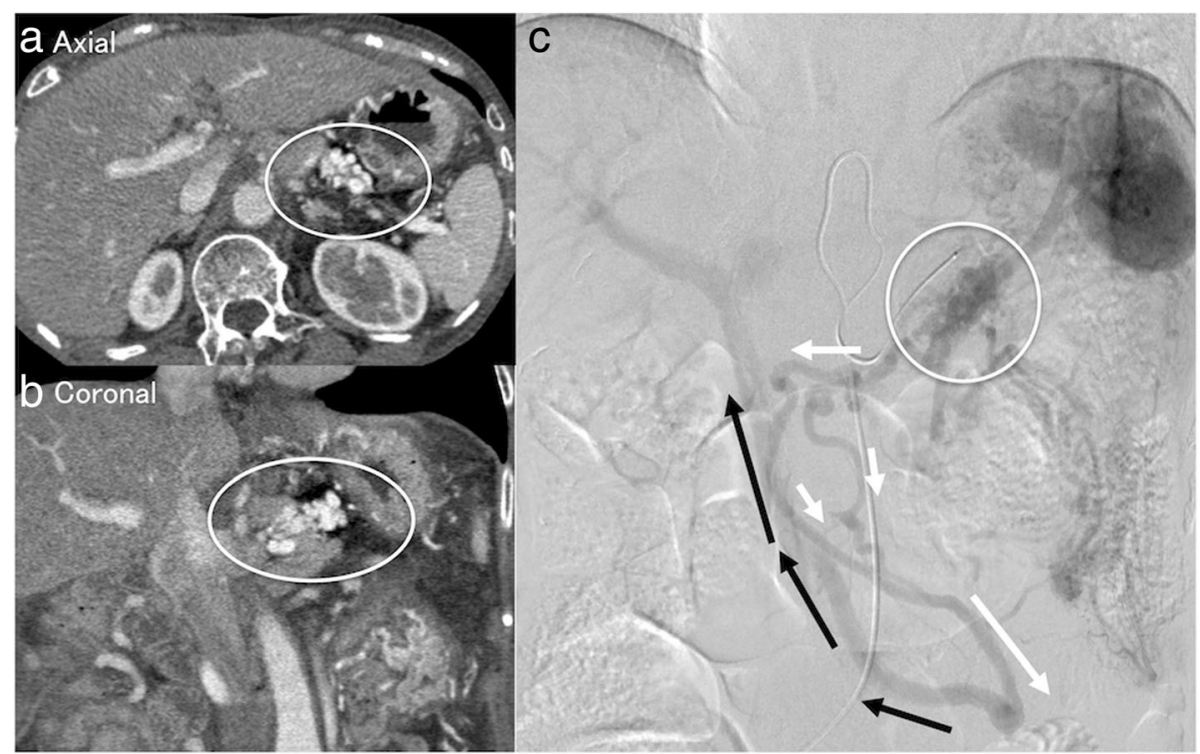

Fig. $\mathbf{2}$ a, b Computed tomography image showing pancreaticojejunostomy varices. c Image of digital subtraction arterial portography from the splenic artery. The flow of splenic vein drain into the varices around the pancreaticojejunostomy (white circle) and finally toward the superior mesenteric vein (black arrow) via the elevated jejunal vein (white arrow) 


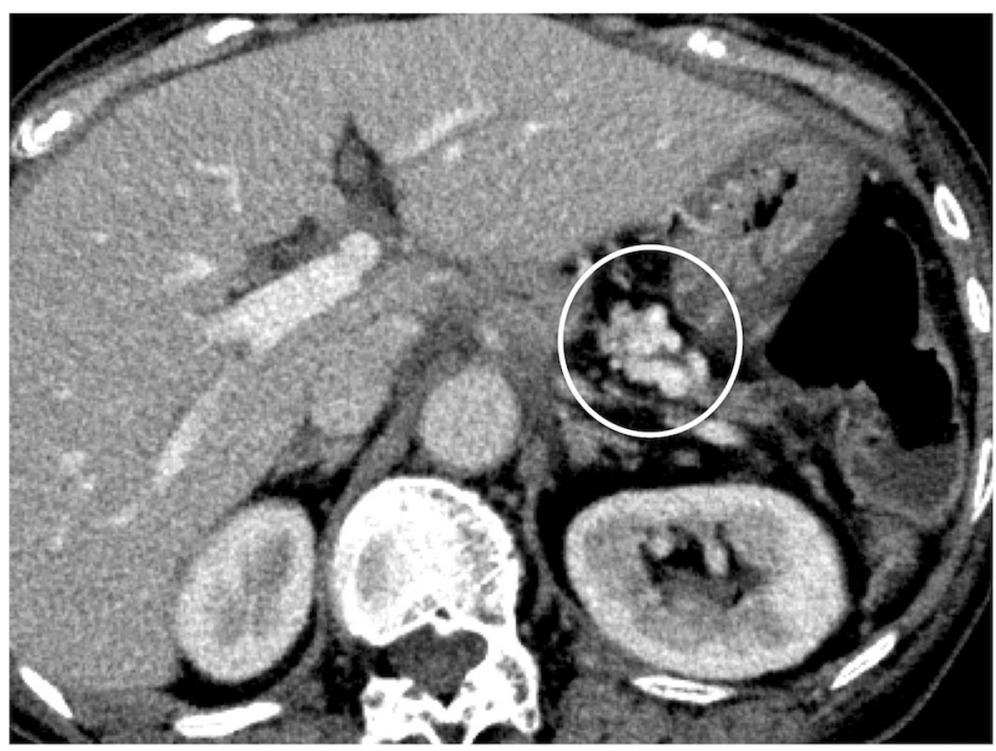

Fig. 3 Pancreaticojejunostomy varices remained by follow-up CT at 3 years after first stage PSE

of the PV and SV in addition to a reconstruction between the PV and superior mesenteric vein (SMV) (Fig. 4). Eighteen months after surgery, he had melena with negative findings on both upper and lower gastrointestinal endoscopic examinations. CT scans revealed varices at a portion of the PJ that communicated with a vein of the elevated jejunal limb and the PV (Fig. 5a, b). We selected obliteration of the varices via a trans-portal-venous approach by puncturing the intrahepatic PV. The varices around the PJ disappeared after obliteration using ethanolamine oleate iopamidol (Fig. 5c, d). Follow- up CT at 1 year after this procedure showed no varices at a portion of the PJ (Fig. 6). His melena had disappeared until his death due to a recurrence of $\mathrm{PC}$ 17 months after IVR.

\section{Discussion}

Previously, some authors have shown that PD without SV reconstruction could cause LSPH [3, 4]. However, until now, there was no definitive procedure to prevent LSPH after PVR without SV reconstruction because certain LSPH mechanisms after a PD were unclear. Gyoten
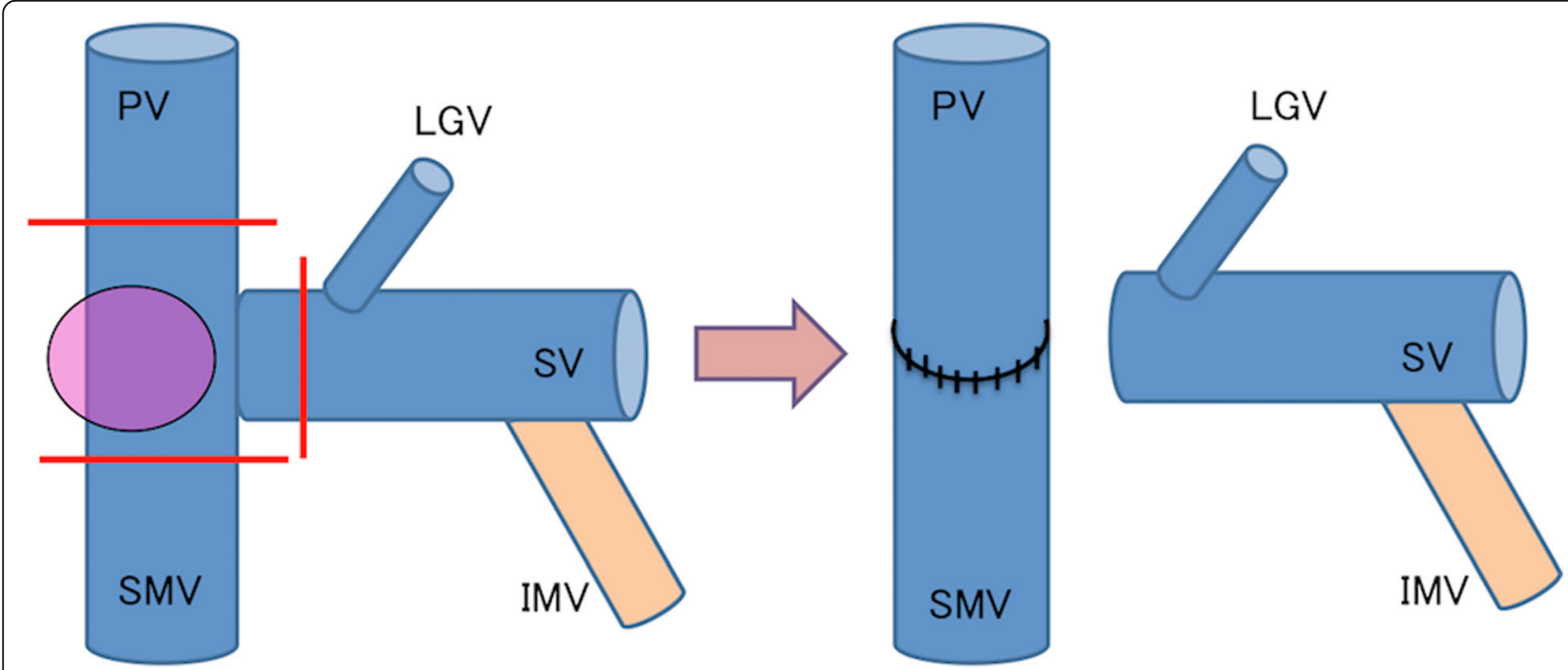

Fig. 4 Pancreaticoduodenectomy combined with concomitant resection of the confluence of the PV and SV. Reconstruction was performed only between the PV and SMV: the IMV was preserved. PV portal vein, LGV left gastric vein, SV splenic vein, IMV inferior mesenteric vein, SMV superior mesenteric vein 


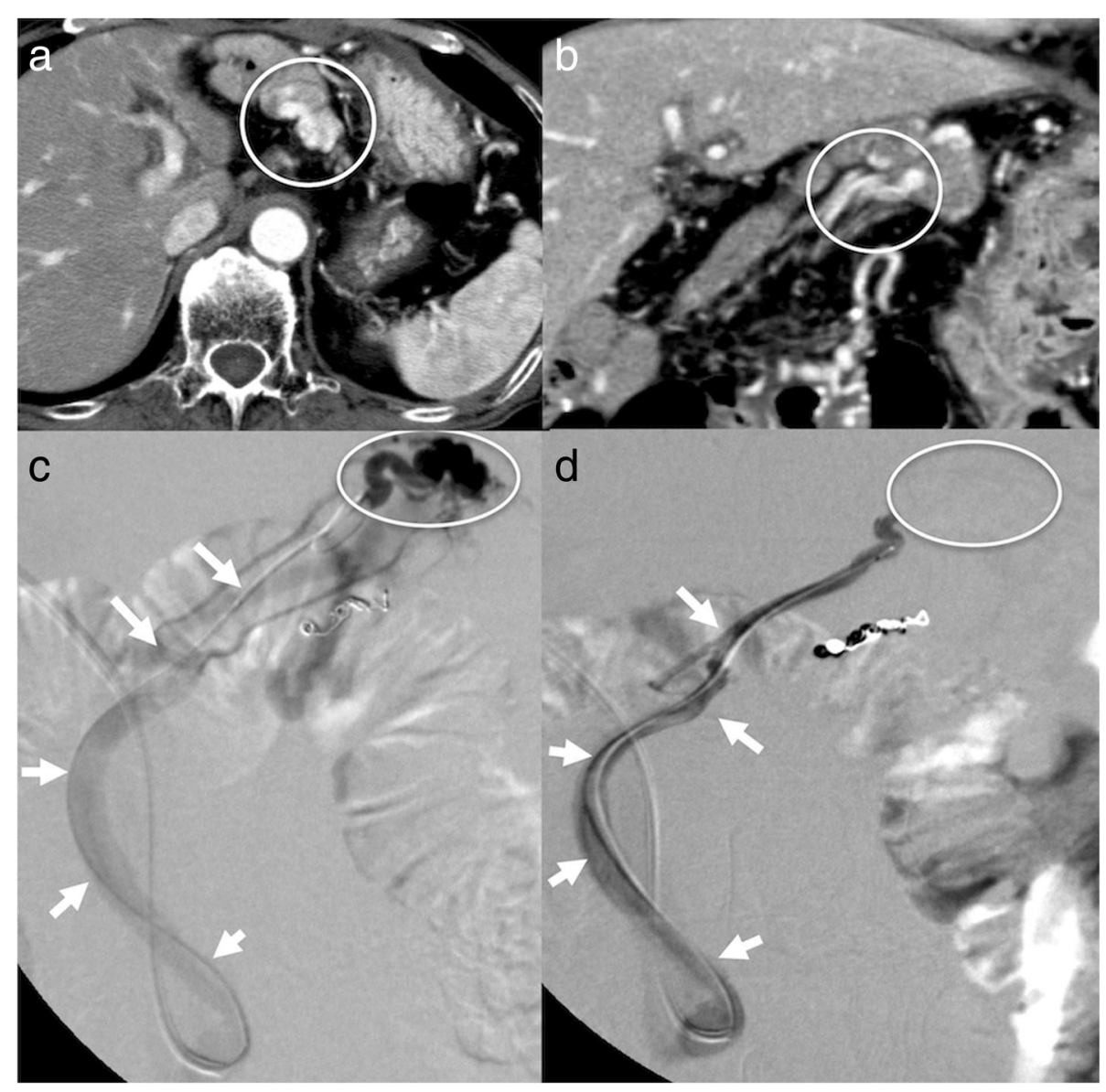

Fig. 5 a, b Computed tomography image showing varices at the pancreaticojejunostomy that communicated with the elevated jejunal and portal veins. $\mathbf{c}, \mathbf{d}$ Image of retrograde trans-portal-venous obliteration (white arrow is the elevated jejunal vein). Retrograde venography before obliteration (c) showing the varices around the pancreaticojejunostomy (white circle). Retrograde venography after obliteration (d) showing that the varices around the pancreaticojejunostomy disappear (white circle)

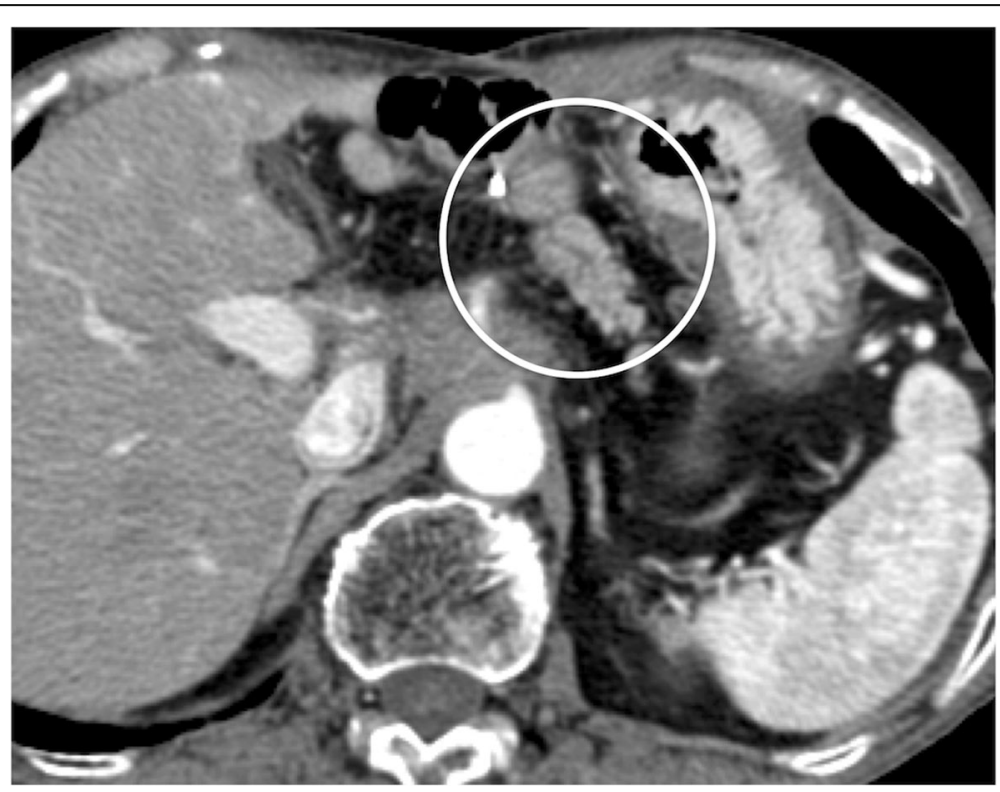

Fig. 6 Follow-up CT at 1 year after procedure showed no varices at a portion of the PJ 
et al. [5] reported that concomitant splenic artery divisions during operations may attenuate the risk of LSPH. Some authors [6, 7] also advocated that preserving the SV-IMV confluence or reconstruction of the SVIMV anastomosis would be useful for preventing LSPH. However, Ono [8] and Ismael et al. [9] showed that SV-IMV anastomosis or SV-IMV confluence preservation was insufficient because blood flow from the SV eventually drains into the SMV via the marginal veins of the colon and/or omentum. Findings of our cases support their findings. The present cases showed that preservation of the SV-IMV flow was not useful in preventing LSPH. One possible reason for the formation of varices at a portion of the PJ is the division of communication from the SV to the greater omentum and marginal veins of the transverse and right colon. Because we usually separate the omentum from the colon when we perform a PD, our experiences supported Ono and Ismael's opinions. Recently, some authors $[10,11]$ have shown that the preservation of collateral veins prevents LSPH. Considering these findings, preservation of many drainage vein of splenic flow may reduce the risk of LSPH.

For intestinal bleeding from a PJ due to LSPH, several types of procedures can be considered: total pancreatectomy, a splenectomy, obliteration of the varices via a trans-portal-venous approach, and a PSE. Previously, several authors have reported that PSE is an effective treatment for acute gastric bleeding due to LSPH [12, 13]. Our first case suggested that PSE would be effective not only for gastric bleeding but also for bleeding from PJs due to LSPHs. PSEs are also thought to be less invasive than splenectomies. However, PSEs could cause severe postoperative reactions such as splenic abscess, sepsis, and splenic ruptures [14]. Wang et al. [15] reported that splenic infarctions following PSEs could be controlled in 60$70 \%$ of patients. However, some recent reports have indicated that a total splenic embolization may be associated with lower rates of splenic abscess formation than partial embolization [16, 17].

In our second case, we selected obliteration of the varices at the PJ via a trans-portal-venous approach because CT scans showed a route from the PV to the varices at a portion of the PJ. This procedure was previously reported by Sakamoto et al. [18] in 2014. This procedure had several benefits that could maintain the splenic arterial flow and approach the varices directly. However, the procedure is highly technical. In our first case, we cannot select obliteration of the varices because the approach to the varices from PV was thought to be difficult due to tortuosity of the vein.

Our cases suggested that IVR could be the first choice for intestinal bleeding at a portion of the PJ due to
LSPH. Furthermore, it is assumed that trans-portal-venous approach is first-choice procedure.

\section{Conclusions}

We presented two types of IVR procedures for intestinal bleeding at a portion of the PJ following PD. The obliteration of the varices in PJ could be first choice procedure.

\section{Abbreviations}

CT: Computed tomography; IMV: Inferior mesenteric vein; IVR: Interventional radiology; LSPH: Left-sides portal hypertension; PC: Pancreatic cancer; PD: Pancreaticoduodenectomy; PJ: Pancreaticojejunostomy; PSE: Partial splenic artery embolization; PV: Portal vein; PVR: Portal vein resection; SMV: Superior mesenteric vein; SV: Splenic vein

\section{Acknowledgements}

We would like to thank Editage (http://www.editage.jp) for English language editing.

Funding

Not applicable.

Availability of data and materials

Not applicable.

\section{Authors' contributions}

HK and TN drafted the manuscript; DA, TS, KT, YN, TA, TN, TT, KO, and SH critically revised the manuscript. All authors read and approved the final manuscript.

Ethics approval and consent to participate

Not applicable.

\section{Consent for publication}

Written informed consent was obtained from the patients for publication of this case report and the accompanying images. A copy of the written consent is available for review by the Editor of this journal.

\section{Competing interests}

The authors declare that they have no competing interests.

\section{Publisher's Note}

Springer Nature remains neutral with regard to jurisdictional claims in published maps and institutional affiliations.

\section{Author details}

'Department of Gastroenterological Surgery 2, Hokkaido University Faculty of Medicine, Kita 15 Nishi 7, Kita-ku, Sapporo, Hokkaido 060-8638, Japan.

${ }^{2}$ Department of Diagnostic and Interventional Radiology, Hokkaido University Hospital, Kita 15 Nishi 7, Kita-ku, Sapporo 060-8638, Japan.

Received: 4 June 2019 Accepted: 30 July 2019

Published online: 08 August 2019

\section{References}

1. Koklu S, Coban S, Yuksel O, Arhan M. Left-sided portal hypertension. Dig Dis Sci. 2007:52:1141-9.

2. Weber SM, Rikkers LF. Splenic vein thrombosis and gastrointestinal bleeding in chronic pancreatitis. World J Surg. 2003:27:1271-4.

3. Fuhrman GM, Leach SD, Staley CA, Cusack JC, Charnsangavej C, Cleary KR, et al. Rationale for en bloc vein resection in the treatment of pancreatic adenocarcinoma adherent to the superior mesenteric-portal vein confluence. Pancreatic Tumor Study Group. Ann Surg. 1996;223:154-62.

4. Bachellier P, Nakano H, Oussoultzoglou PD, Weber JC, Boudjema K, Wolf PD, et al. Is pancreaticoduodenectomy with mesentericoportal venous resection safe and worthwhile? Am J Surg. 2001;182:120-9.

5. Gyoten K, Mizuno S, Nagata M, Ogura T, Usui M, Isaji S. World J Surg. 2017; 41(8):2111-20.

6. Tamura K, Sumi S, Koike M, Yano S, Nagami H, Nio Y. A splenic-inferior mesenteric venous anastomosis prevents gastric congestion following 
pylorus preserving pancreatoduodenectomy with extensive portal vein resection for cancer of the head of the pancreas. Int Surg. 1997;82:155-9.

7. Ferreira N, Oussoultzoglou E, Fuchshuber P, Ntourakis D, Narita M, Rather M, et al. Splenic vein-inferior mesenteric vein anastomosis to lessen left-sided portal hypertension after pancreaticoduodenectomy with concomitant vascular resection. Arch Surg. 2011;146:1375-81.

8. Ono Y, Matsueda K, Koga R, Takahashi Y, Arita J, Takahashi M, et al. Sinistral portal hypertension after pancreaticoduodenectomy with splenic vein ligation. Br J Surg. 2015;102:219-28.

9. Rosado ID, Luis SB, Sanchez A. Pattern of venous collateral development after splenic vein occlusion in an extended Whipple procedure (Whipple at the splenic artery) and long-term results. J Gastrointest Surg. 2017;21:516-26.

10. Haruyoshi T, Akimasa N, Kenji O, Kiyotsugu I, Yukiko O, Hironobu K, et al. Splenic vein reconstruction is unnecessary in pancreatoduodenectomy combined with resection of the superior mesenteric vein-portal vein confluence according to short-term outcomes. HPB. 2017;19(9):785-92.

11. Tanaka M, Ito H, Ono Y, Matsueda K, Mise Y. Impact of portal vein resection with splenic vein reconstruction after pancreatoduodenectomy on sinistral portal hypertension: who needs reconstruction? Surgery. 2019;165(2):291-7.

12. Sato T, Yamazaki K, Toyota J, Karino Y, Ohmura T, Suga T. Gastric varices with splenic vein occlusion treated by splenic arterial embolization. J Gastroenterol. 2000;35:290-5.

13. Tsuchida S, Ku Y, Fukumoto T, Tominaga M, Iwasaki T, Kuroda Y. Isolated gastric varices resulting from iatrogenic splenic vein occlusion: report of a case. Surg Today. 2003;33:542-4.

14. Madoff DC, Denys A, Wallace MJ, Murthy R, Gupta S, Pillsbury EP, et al. Splenic arterial interventions: anatomy, indications, technical considerations, and potential complications. Radiographics. 2005;25:S191-211.

15. Wang $Q$, Xiong B, Zheng CS, Liang M, Han P. Splenic arterial embolization in the treatment of severe portal hypertension due to pancreatic diseases: the primary experience in 14 patients. Cardiovasc Intervent Radiol. 2016;39:353-8.

16. He XH, Gu JJ, Li WT, Peng WJ, Li GD, Wang SP, et al. Comparison of total splenic artery embolization and partial splenic embolization for hypersplenism. World I Gastroenterol. 2012;18:3138-44.

17. N'Kontchou G, Seror O, Bourcier V, Mohand D, Ajavon Y, Castera L, et al. Partial splenic embolization in patients with cirrhosis: efficacy, tolerance and longterm outcome in 32 patients. Eur J Gastroenterol Hepatol. 2005;17:179-84.

18. Sakamoto N, Yamaguchi M, Sofue K, Muradi A, Idoguchi K, Okada T, et al. Modified interventional obliteration for variceal hemorrhage from elevated jejunum after pylorus-preserving pancreatoduodenectomy. Jpn J Radiol. 2014;32:487-90

\section{Submit your manuscript to a SpringerOpen ${ }^{\circ}$ journal and benefit from:}

- Convenient online submission

- Rigorous peer review

- Open access: articles freely available online

- High visibility within the field

- Retaining the copyright to your article

Submit your next manuscript at $\boldsymbol{\nabla}$ springeropen.com 